\title{
Habitat and inhabitant
}

The first and last articles in this issue of arq draw from the work of John Hejduk (1929200o), the architect, artist, and writer who became famous as much for his teaching and poetry as his designs. Andrew Carr's opening text recalls Lily Chi's reflection on Hejduk's distinctive projects - which, she says, had a specific, scripted quality where it was "no longer possible to tell what is being "designed", the habitat or the inhabitant [...]'. Carr's series of design studies (pp. 94-112) propose architectural objects and their rhythms of inhabitation to explore the temporality of architecture. Carr talks about ideas of 'succession' and 'duration' in order to investigate what K. Michael Hays called (when writing about Hejduk's work) 'the architectural chronotope', meaning the artistic connection of spatial and temporal relationships.

In a similar spirit, this issue of arq focuses on the co-production of habitat and inhabitant in architecture and text. Specifically, it addresses how stories told about spaces and their users reinforce the identity of those places and people.

Samantha Martin-McAuliffe's article recalls Plato's ancient dialogues (pp.131-140). The dialogues nearly always acknowledge the location of a given conversation, she observes, whereas modern scholarship rarely ventures beyond passing references to its setting. Importantly, she shows how 'speech and its attendant gestures were instrumental to the urban order of ancient cities'. Kristina Fridh, meanwhile, examines the diverse work of Toyo Ito and Kengo Kuma to find that they share a connection to the Japanese tradition where 'space is a changeable experience and a mental process, not an object, and the basis of being subjective is that there is something unpredictable and uncompleted [...] in the experience' (pp. 113-130).

Hyon-Sob Kim's article focuses on how Korean architecture was narrated in the West in the 1960s through two Expo pavilions, sited in New York and Montreal, designed by Chung-Up Kim and Swoo-Geun Kim, respectively (pp. 155-170). In contrast, Bob Giddings and Oliver Moss examine ideas about local rather than national identity. They recount the story of a housing project designed by Gordon Ryder and Peter Yates at Kenton Bar, Newcastle-upon-Tyne, UK, also from the 196os (pp. 150-154). Giddings and Moss illustrate how the houses narrated the imagery and everyday settings of modernity, and how residents there continue to identify with their estate through stories told about its past. 
The stories that Gill Matthewson examines are less directly about habitat and inhabitant and more about the body of architects involved in their design. Her article collects evidence which establishes that 'there is clearly asymmetrical attrition from the profession by gender' in Australia, 'which strongly suggests that gendered biases and stereotypes play powerful roles in determining tenure in the profession'.

To conclude, Jane Anderson and Colin Priest return to John Hejduk's work. They examine the interplay between reality and imagination in student design-build projects that they supervised at The Story Museum in Oxford, UK. They turn to Hejduk's work because, for them, it aids the reappraisal of conceptions of reality and imagination by different agents in the architectural design process.

THE EDITORS 